\title{
Migración y cambios socioeconómicos en la comunidad de Zoogocho, Oaxaca
}

\section{Donato Ramos Pioquinto*}

La migración como parte de la realidad social es un proceso multidimensional históricamente determinado en el cual se interrelacionan factores físico-naturales, socioeconómicos, culturales y psicosociales. Cada una de las áreas especificas en que tiene lugar está vinculada a un contexto que se desvanece en la inmensidad geográfica y temporal. De ahí que, para comprender el fenómeno, es menester establecer diversos niveles de análisis de los factores tanto internos como externos que en él intervienen, en un orden de prioridades cambiante en situaciones concretas.

El estudio de la migración y la dinámica socioeconómica en la comunidad de Zoogocho, Oaxaca, es una muestra de lo que ocurre en el medio rural cuando los campesinos indígenas se relacionan con el exterior. La penetración de los valores socioeconómicos y culturales ajenos altera las estructuras familiares y comunitarias, al grado de que los recursos disponibles llegan a ser insuficientes para competir con la sociedad que impacta, lo cual implica un desplazamiento poblacional cada vez más complejo, cuyas manifestaciones, causas y consecuencias varían a través del tiempo, tanto en el lugar de origen como en los de destino. Por consiguiente, las diversas características que adopta el proceso no permiten afirmar que sus manifestaciones en Zoogocho sean idénticas en otras comunidades.

\section{Introducción}

La investigación científica aborda partes de la inmensurable realidad para analizar situaciones concretas. Las diversas dimensiones de un fenómeno social particularmente demandan diversos elementos de explicación que deben considerarse para delimitar un objeto de estudio. De esta forma abordamos el caso específico de la comunidad campesino-indígena de Zoogocho, Oaxaca, que ha sufrido cambios sustanciales en su estructura económica y sociocultural a raíz del fenómeno migratorio, como consecuencia de la agudización del impacto de la sociedad dominante, desde principios del siglo $\mathrm{xx}$.

En esta comunidad destaca un progresivo desplazamiento de la población hacia tres principales lugares de destino de 1940 a 1990: la ciudad de Oaxaca, el valle de México y la ciudad de Los

* Investigedor del Instituto de Investigaciones Sociológicas de la Universidad Autónoma Benito Juárez de Oaxaca. 
Ángeles, California, EUA, pero no sólo como éxodo, sino también por la influencia que ejercen los migrantes en las estructuras familiares y comunitarias. El flujo de dinero proveniente de la migración ha logrado cambios positivos en los niveles de vida, en términos de bienestar social, pero no así en cuanto a la conservación de las costumbres o tradiciones de la colectividad, principalmente en lo que respecta al "sistema de cargos" como eje rector de la comunidad, que se está configurando según las transformaciones culturales que está sufriendo y, sobre todo, que ya no puede operar debido a la constante disminución de la población.

Para analizar lo anterior, se parte de que el estado de Oaxaca, situado al sureste del país, presenta una heterogeneidad no sólo en su aspecto geográfico sino también en los aspectos socioeconómico, político y cultural. Las diversas problemáticas que presenta en los niveles regional y microrregional implican diversas formas de migración, lo que es determinante en la configuración actual de su población en general.

En su gran mayoría, la población oaxaqueña es campesinoindigena; sus miembros trabajan la tierra como pequeños propietarios o usufructuarios, con rasgos socioculturales y políticos específicos, que se encuentran sometidos a una relación de colonización. En el estado existen dieciséis grupos étnicos que se identifican no sólo por la lengua sino por un conjunto especifico de relaciones económicas, sociopolíticas y culturales sustentadas en la economía campesina y en el "sistema de cargos", este último como núcleo de la organización social comunitaria.

La economía campesina se basa en la agricultura de temporal, complementada con actividades artesanales y comerciales. El campesino hace producir directamente la tierra con instrumentos de labranza ancestrales; casi no compra fuerza de trabajo, salvo en ocasiones especiales, pues la unidad de producción básica la integran los propios elementos de su familia, según edad y sexo. En la socialización de este proceso productivo y en la división social del trabajo encontramos la ayuda mutua entre las unidades familiares y el trabajo colectivo por barrios o por comunidad.

Generalmente, la economía campesina presenta un nivel productivo bajo; casi la totalidad de lo que se produce se destina al autoconsumo (para la reproducción de la unidad familiar y una reserva para un nuevo ciclo productivol y sólo una mínima parte se lanza al intercambio, en donde el campesino da parte de su producto por otro que necesita, ya sea porque no lo puede producir o porque su producción le resulta deficitaria.

Los productos de esta agricultura no son suficientes para la subsistencia familiar de los campesinos, por lo que se tienen que 
complementar con la actividad artesanal, con amplia participación de la fuerza de trabajo femenino e infantil; labran la madera, trabajan el barro, la piel, el algodón, la lana de borrego, la seda de gusano, el carrizo, la palma, el ixtle y otros productos semisilvestres. Cada región o cada comunidad se caracteriza por la práctica de alguna de las actividades no agrícolas.

A diferencia de los productos agrícolas, las artesanías se destinan mayoritariamente al intercambio, en los mercados regionales y en las tiendas. En este proceso, para algunos productos existe, por un lado, una red de acaparadores o intermediarios y, por otro, el intercambio con las mercancías (propias de la sociedad dominante) es cada vez más desigual en detrimento de los productos agrícolas y artesanales en general, mismos que son sustituidos paulatinamente por los de metal y plástice con alteración de los precios regionales.

Sobre esta economía campesina se erige una organización social como factor de reproducción de los patrones de vida comunitaria, basada en el "sistema de cargos", en el cual se interrelacionan funciones políticas, cívicas y religiosas. Los cargos que conforman este organismo se presentan gradualmente como un deber de todos, con las mismas posibilidades de ascenso hacia la posición social más privilegiada. Sin embargo, existe dentro de cada comunidad una estratificación definida por la concentración de la riqueza, la posición social o el poder polftico que de alguna forma influye en el funcionamiento de este sistema.

En este tipo de organización social se configura un proceso de continuidad y cambio que se manifiesta, por un lado, en el afán de conservar los patrones de vida autóctonos y, por otro, en la tendencia a reajustarlos o reorientarlos ante los límites impuestos desde el exterior por la sociedad dominante. La constante transformación que sufre responde en última instancia a los intereses y a las necesidades de la expansión capitalista. De ahí que, el "sistema de cargos" puede ser un elemento de nivelación, redistribución, legitimación o expropiación de la riqueza en la comunidad. según su relación con la sociedad dominante.

En el "sistema de cargos" se unifica la forma ancestral de mando (como la Junta de Elección de Representantes y el Consejo de Ancianos que se formaliza con el bastón de mando que se deposita ceremonialmente) con el Ayuntamiento Constitucional (como fundamento de la organización política estatal y nacional electa por una solemne asamblea general). Dentro de esta organización existe una estrecha relación entre los cargos políticos y religiosos, cuyos funcionarios ejercen con base en los principios legales"y las tradiciones locales. Los puestos y los servicios que se prestan obli- 
gatoriamente son gratuitos y se desempeñan por elección popular durante un año generalmente, a cambio de un gradual prestigio y posición social dentro de la comunidad. En este proceso, la Autoridad Municipal se encarga de coordinar las actividades colectivas conocidas como "tequio", en las que todos los hombres, desde la adolescencia, proporcionan mano de obra en determinados días del año y, en algunas comunidades, las mujeres solteras y viudas participan según las costumbres o tradiciones locales, proporcionando, por ejemplo, agua u otra bebida durante el "tequio"; materiales de la región como madera, grava, arena o piedra; como mano de obra contratada o aportando dinero en efectivo.

Dentro de la problemática anterior se ubica la región de la Sierra Norte de Oaxaca, la cual se compone de una diversidad de comunidades campesino-indígenas, cada una formada por un conjunto de individuos que se identifican entre sí y definida por un territorio, una economía campesina y una organización social, política y religiosa específica, cuya relación con la sociedad dominante implica una gama de problemas socioeconómicos en contra de la población autóctona, lo que obliga a determinados elementos a buscar alternativas de sobrevivencia fuera de su comunidad, dándose así un proceso migratorio que a través del tiempo ha llegado a ser un fenómeno sumamente complejo, que ha adoptado características especificas en situaciones concretas.

La migración es un proceso multifacético de desplazamiento poblacional, cuya causa es la necesidad o la aspiración de superar una insatisfacción emanada de factores físico-naturales, socioeconómicos, culturales y psicológicos, históricamente determinados, que crean cambios en cada una de las áreas en que se produce. La carencia o la deficiencia de satisfactores en unas áreas y la presencia de los mismos en otras obligan a ciertas personas o grupos sociales a cambiar su residencia, regional o extrarregionalmente, en forma definitjva o por un lapso determinado, en relación con la dinámica socioeconómica de una sociedad más amplia a la cual pertenecen.

Las diferentes formas y modalidades que ha adoptado el fenómeno han suscitado una serie de controversias teóricas. Así, los diversos modelos explicativos que se han planteado responden a determinados puntos de vista y objetivos de los cientificos sociales que lo abordan (antropólogos, demógrafos, economistas, ecólogos o sociólogos) y que han apuntado hacia dos enfoques: el histórico-estructural y el de la "modernización". ${ }^{1}$ El primero sostiene

\footnotetext{
1 Véase Lourdes Arizpe, "Migración y marginalidad", en Héctor Díaz-Polanco et al.. Indigenismo. modernización y marginalidad. Una revisión crítica, México, ci's y Juan Pablos Editor, 1980: 213.
} 
que la base teórica de los procesos más amplios es la que nos servirá para explicar la migración, ya que ésta deriva de aquéllos en situaciones determinadas. El segundo considera que el enfoque anterior aun cuando no es suficiente, es necesario, puesto que en términos de selectividad hay que explicar por qué en áreas con condiciones similares, en unas comunidades se produce la migración y en otras no, por qué en una comunidad unas familias migran y otras no lo hacen, y por qué aun en una familia, determinados miembros son los que se desplazan.

A partir de lo anterior, consideramos que para detectar las distintas dimensiones del proceso migratorio debe establecerse un orden de prioridades de los factores que lo hacen posible, independientemente del tamaño del grupo estudiado, ya que tanto las condiciones generales, llámense externas, objetivas, mediatas o necesarias, como las particulares, internas, subjetivas, inmediatas o suficientes, se interrelacionan en mayor o menor grado en la realidad.

En primer lugar, los factores físico-naturales. El relieve, el clima y los recursos naturales influyen en que el asentamiento de algunos núcleos de población esté en lugares estratégicos, emanados de la posibilidad de acceso a los terrenos de la productividad de algunos de ellos y de otros en situaciones contrarias. Por consiguiente, la relación entre los recursos y la población es variada y llega a producir cierta migración regional, ${ }^{2}$ que puede agudizarse o reorientarse con otros fenómenos ocasionales o casuales (heladas, inundaciones, derrumbes, sequías, plagas y otras situaciones coyunturales] y configurarse en la instancia económica y social.

En segundo lugar, las condiciones socioeconómicas. Las diferentes características entre las comunidades y las relaciones de producción entre estratos sociales diferentes implican cierto fenómeno migratorio, es decir, la demanda de mano de obra o de productos de consumo en unas comunidades, y la no autosuficiencia económica en otras, obliga a determinadas personas o familias a migrar para satisfacer sus necesidades, en calidad de campesinos, artesanos, jornaleros o comerciantes ambulantes. ${ }^{3}$ En un princi-

\footnotetext{
2 Esta relación no siempre produce migración, ya que algunos de los que no pueden satisfacer sus necesidades con sus propios recursos naturales prosperan en otras actividades no agrícolas, como los artesanos y los comerciantes, y de esta forma contrarrestan el desequilibrio entre el aumento de la población y la producción de satisfactores que establece la teoria malthusiana.

3 Este proceso puede suceder independientemente de los recursos naturales, ya que éstos pueden estar concentrados en pocas manos y, en consecuencia, lo que producen ya no es para cubrir las necesidades de la población, sino para incre-
} 
pio este proceso se da a nivel regional, pero al ir ampliando su red de acción los migrantes encuentran los valores económicos y socioculturales urbanos propios de la sociedad dominante, y empieza el intercambio desigual de productos, en detrimento de la producción local, y la alteración de los precios y las retribuciones regionales. Por consiguiente, la migración tiende a ser extrarregional y a dirigirse a los centros urbanos, y paralelamente entran en juego valores extraeconómicos.

En tercer lugar, los elementos socioculturales y psicológicos. Con la ampliación de las relaciones comerciales, la construcción de caminos, la creación de servicios educativos, el establecimiento de dependencias de gobierno y la penetración de medios masivos de comunicación, primeramente en las comunidades ubicadas estratégicamente, el impacto de los valores socioeconómicos y culturales de la sociedad dominante es cada vez mayor. La desventaja económica y la discriminación cultural configuran el proceso migratorio y éste adquiere mayor complejidad; se produce una progresiva emigración rural-urbana extrarregional (hasta de índole internacional) en donde ya se combinan las causas internas con las externas, tanto económicas como socioculturales y, por otro lado, una inmigración, también extrarregional pero de índole urbano-rural. En otros términos, por un lado salen campesinos indígenas hacia los centros urbanos a trabajar, y algunos a estudiar, y por otro, llega a la región gente urbana o urbanizada en calidad de comerciantes, profesores, estudiantes o empleados.

En esta dinámica socioeconómica se hace más notoria la influencia de la migración y aparecen las motivaciones individuales como causas suficientes para emigrar. La posesión de una profesión, el consumo de productos industrializados, el uso de vestido y calzado propios de las ciudades, la posesión de aparatos eléctricos o electrónicos, la construcción de casas "modernas", la adquisición de carros o camionetas y la invitación directa de los migrantes motiva de una u otra manera a los campesino-indígenas a desplazarse para trabajar, estudiar o aventurarse dentro del país o en el extranjero. ${ }^{4}$ De esta forma, y en el plano psicosocial principalmente, los migrantes participan como agentes motivadores de la migración.

mentar el poderío de un estrato social; o bien, aunque se tenga acceso a los recursos, la misma estratificación social puede obstruir o anular su aprovechamiento.

${ }^{4}$ Las motivaciones también presentan diversas formas según las relaciones familiares, culturales, psicosociales y la naturaleza misma de los individuos, ya que cada uno es una realidad especifica que capta o absorbe lo externo de manera distinta a los demás. 
Por otra parte, la vinculación, históricamente determinada, de un área específica a un contexto mayor, en este caso una comunidad a la sociedad dominante, es lo que determina el espacio geográfico del proceso migratorio. De ahí que, al hablar de una migración regional nos referimos al espacio en el cual el migrante se desenvuelve con sus características originales, y cuando se desborda hacia un contexto en donde predominan elementos ajenos a su origen, entonces el desplazamiento se torna extrarregional, y puede prolongarse a un plano internacional.

Lo anterior vale también cuando se trata de la duración del fenómeno, que no depende de lapsos específicos sino de la vinculación o la desvinculación del migrante con respecto a su lugar de origen, es decir, migración temporal o permanente.

En la primera, los migrantes conservan su grado de parentesco. El que es jefe de familia, por ejemplo, lo sigue siendo en el sentido de que sus familiares (cónyuge e hijos) lo consultan o esperan su regreso para tomar decisiones. Asimismo, los hijos que emigran siguen sujetos a los padres, lo que quiere decir que los migrantes continúan siendo miembros de la familia, independientemente de su ausencia, y que no tienen otra familia más que la original. Estos migrantes temporales generalmente practican actividades diversas y su posición dentro del proceso de trabajo suele ser precaria, y no adoptan fácilmente los patrones de vida del lugar de destino, ya que su objetivo no es quedarse en él sino retornar al de origen; su cosmovisión y sus perspectivas siguen apuntando fijamente hacia el lugar de procedencia.

La migración se vuelve permanente cuando se rompe el esquema anterior, cuando ya es importante el lugar de destino para la configuración socioeconómica de los migrantes, se marca la diferencia con el lugar de origen y se toman decisiones de cualquier índole por lugar de residencia. Esto se produce paulatinamente conforme adquieren estabilidad en la estructura ocupacional; cuando forman otro hogar o familia en el lugar de destino, adoptan los valores socioculturales de éste y adquieren los bienes materiales necesarios para su integración. Lo permanente de este fenómeno no siempre significa una ruptura con su lugar de origen, ya que es fundamental su apoyo económico y sociocultural en las unidades familiares y en las estructuras comunitarias a través de sus organizaciones formales en el lugar de destino.

Al considerar los niveles de análisis expuestos es posible determinar las condiciones internas y externas de la migración en su conjunto, como inmigración y emigración, en donde la magnitud, 'a modalidad, el ritmo, la duración, los agentes y las consecuencias adoptan características particulares en cada momento y 
en cada lugar donde se origina y se desarrolla. De esta forma se presenta el caso de la comunidad de Zoogocho, ${ }^{5}$ situada a $110 \mathrm{~km}$ hacia el nornoreste de la ciudad de Oaxaca, cuya población es de 534 nativos, 210 inmigrantes y 753 emigrantes.

El presente trabajo es una exposición sucinta de los hallazgos más sobresalientes de una investigación realizada en 1987 con los siguientes instrumentos: ${ }^{6}$

a) Un censo general a las 176 unidades familiares de la localidad, que aparece con el nombre de Censo Poblacional de Zoogocho, Oaxaca, 1987, para recopilar datos sobre los aspectos económicos y sociodemográficos de los habitantes en sus respectivas familias.

b) Una guía de entrevistas a 12 informantes clave (8 en Zoogocho, 2 en la ciudad de Oaxaca y 2 en el valle de México) para captar información sobre las características socioeconómicas generales de la comunidad y de las 44 viviendas vacías que en ella existen.

c) Un cuestionario que se practicó a 131 emigrantes seleccionados aleatoriamente: 69 (60\%) de los 115 residentes en la ciudad de Oaxaca, 45 (15\%) de los 302 en el valle de México y 17 (6\%) de los 336 en Los Ángeles, California, EUA (estos últimos fueron captados a su regreso en la fiesta patronal de la comunidad en el mes de agosto) para recopilar información acerca del proceso migratorio de los migrantes mismos, a través de su propia experiencia.

Por otro lado, se reconstruyeron historias de vida, se analizaron algunos documentos obtenidos del Archivo Municipal y de las organizaciones formadas en cada uno de los lugares de destino de los emigrantes, y se captó información a través de la observación ordinaria y participante como integrante de la comunidad objeto de estudio.

Posteriormente se procesó la información, y se representó la cuantificable en cuadros y gráficas. De esto es necesario señalar que para la emigración solamente se consideró a los 753 emigrantes permanentes, es decir, a los que en el momento de aplicar el censo tenfan un año o más de vivir fuera de la comunidad con las características señaladas anteriormente, ya que de 1940 a 1987 sólo se detectó un total de 142 elementos que habian participado

5 Nombre oficial: San Bartolomé Zoogocho; categoria política: Pueblo, y categoría administrativa: Municipio.

${ }^{6}$ Cabe mencionar que en esta presentación se incluyen datos actualizados hasta 1990. 
alguna vez en la emigración temporal, cuya influencia en los patrones de vida locales es insignificante en comparación con la ejercida por las permanentes. Asimismo, se descubrió que durante el mismo periodo, se han muerto 49 zoogochenses que vivían permanentemente fuera de su lugar de origen, y 37 que habían emigrado en forma temporal.

Lo anterior se justifica porque durante las últimas décadas son los emigrantes permanentes los que han introducido cambios radicales en la comunidad y también porque las cifras de los otros, tanto de los temporales como de los muertos, están distribuidas con poca variación a lo largo del periodo abarcado. Por consiguiente, no alteran sustancialmente a las tendencias presentadas.

Finalmente se estructura el trabajo en dos capítulos: en el primero se señalan las características generales de la comunidad y sirve de contexto para el proceso migratorio que se aborda en el segundo; en éste se presenta el fenómeno desde sus orígenes, las diversas características que ha adquirido de 1940 a 1990 por lugar de destino y sus efectos en el lugar de origen. De esta forma se trata de mostrar que la migración rural está relacionada con la intensidad del impacto de la sociedad dominante en las comunidades campesino-indígenas.

\section{Generalidades}

En el área central de la Sierra Norte de Oaxaca se localiza un conjunto de 15 comunidades zapotecas con características geoeconómicas y socioculíurales similares; 12 pertenecen al distrito de Villa Alta (Solaga, Tabaá, Tavehua, Xochixtepec, Yalina, Yatzachi el Alto, Yatzachi el Bajo, Yohueche, Yojovi, Zoochila, Zoochina y Zoogocho) y 3 al de Ixtlán (Guiloxi, Laxopa y Yahuío). El centro de este sector es el municipio de Zoogocho, en donde los jueves se efectúa uno de los mercados semanales más grandes y significativos de la región, y en donde se concentran diversas instituciones oficiales.

Acerca de sus orígenes, no existen datos precisos sobre la fundación de Zoogocho; las fuentes de información al respecto se limi$\tan$ a relatos legendarios heterogéneos. Sin embargo, los vestigios de algunas tumbas arqueológicas (oquedades, piedras labradas y otros utensilios) hallados en la localidad y en sus alrededores parecen indicar la existencia de pequeños núcleos de población característicos de la época prehispánica posclásica. Por otra parte, se ha descubierto un documento en el Archivo General de la Nación, en el cual se menciona que Yolozee, abuelo de los de Zoogo- 
cho, fue bautizado el sábado 8 de abril de 1521 "Quando [sic] llegó el Exmo. SSro. Dn. Fernando Cortez y Monrroj Marqués del Valle ... bino (sic) con dos frailes uno se llamaba frai Domingo Tequinaca y otro frai Bartolomé de Olmedo", 7 lo que quiere decir que antes de la invasión española ya existían estos núcleos.

En cuanto a su etimología, Zoogocho quiere decir "sobre ciénega" en la lengua zapoteco-serrana, ${ }^{8}$ lo que no responde a la realidad, ya que el lugar es sumamente seco; empero existe una versión de que sus fundadores procedieron de Lachixila, comunidad ubicada más al norte del distrito de Villa Alta casi en los limites con los de Tuxtepec e Ixtlán, un lugar donde existen pantanos y que para imprimirle un sello de su origen le dieron este nombre.

Se relata también que las primeras generaciones no tuvieron conflictos de ninguna índole, pero con el correr del tiempo fueron llegando otros núcleos a sus alrededores y se hizo necesaria la definición de sus límites territoriales y, en consecuencia, surgieron las primeras manifestaciones de inconformidad. ${ }^{9}$

Entre los acontecimientos más relevantes que han llegado a afectar la tranquilidad de la población tenemos, por un lado, la arbitrariedad en la delimitación territorial y, por otro, la disputa por el mercado, ${ }^{10}$ que culminaron en un ataque armado en 1931 [Zoochina, apoyada por Yatzachi el Alto y Tavehua, invadió territorio y Zoochila peleó el mercado), en el cual Zoogocho perdió terrenos pero logró retener el tianguis. Posteriormente ha vuelto la calma, el intento de Solaga de trasladar el mercado a su pueblo a princi-

${ }^{7}$ En esta fecha se bautizaron siete representantes o "caciques" de cuatro pueblos en el rfo Yoxidon (Yeg'o Zadún). a) Zoogocho: Don Juan Martín Yolozee (Yolozé, Yolozeche, Yolocehe, Yolozeeh o Yoloceh); b) Solaga: Don Juan Martín Balachila, Don Bartolomé Martín Yalao Lachixoza [Laxhixoza) y Don Bartolomé Martín Thiolana [Tiolana); c) Tabáa: Don Juan de Mendoza Velasco Thiadela (Diadela) y Don Juan Pérez de Velasco Becuadfene, y d) Tavehua: Don Juan Thilaa Lachi Zoguía. Véase Julio de la Fuente, "Testamento de los Caciques de Solaga", en Anales del Instituto Nacional de Antropología e Historia, t. III, México, INAH-SEP, 1949: 185-189.

${ }^{8}$ Cfr. José María Bradomín (1980), Toponimia de Oaxaca. Crítica etimológica, s.e., pp. 301-302.

Se sabe que los primeros pobladores de Yalina, no soportando las acometidas de las fieras y el intenso frío en las faldas del cerro "La Cuarentena", bajaron y solicitaron a los habitantes de Zoogocho les permitieran asentarse en sus terrenos a cambio de darles acceso a la explotación de sus montes. Sin embargo, al lograr su objetivo invalidaron el convenio. Actualmente Zoogocho colinda con cinco comunidades (Solaga, Tavehua, Yalina, Yatzachi el Alto y Zoochina) que lo han circunscrito en un área de $22.96 \mathrm{~km}^{2}$, según el Censo General de Población y Vivienda de 1960.

${ }^{10}$ La disputa por el mercado tiene sus raíces en el siglo xvili. Su héroe defensor, José Jacinto de Santiago, murió en mayo de 1807. 
pios de los años cuarenta no trascendió, y la negación del agua por parte de Yalina en los últimos años se ha resuelto hasta el momento sin mayores problemas.

En cuanto a las actividades económicas, en Zoogocho se ha practicado desde siempre la agricultura de temporal. El cultivo de maíz, frijol, chile, calabaza, café, caña de azúcar y una variedad de frutos se realiza con métodos e instrumentos rústicos y fuerza de trabajo familiar complementada con la ayuda mutua, "gu'zon", y en ocasiones con mano de obra asalariada. Los productos se destinan fundamentalmente al autoconsumo. Sin embargo, no son suficientes para la subsistencia familiar, por lo que se complementan con otras actividades.

Entre las artesanías oriundas que se practicaron en Zoogocho y que se han extinguido, encontramos la cerámica, los cacles de ixtle para calzado de mujer, el aceite inflamable de higuerilla y los sombreros de lana de borrego, y entre las que se siguen practicando tenemos los tejidos de cintura, las velas de sebo de res, la pirotecnia, la panadería, la huarachería y la cestería de carrizo.

Otra de las características de esta economía es el intercambio comercial. A través de largos y cansados "viajes" los zoogochenses fueron ampliando su red de relaciones económicas y socioculturales entre los diversos subgrupos étnicos del zapoteco serrano. Por consiguiente, se diversificaron los productos de intercambio: agrícolas, artesanales, marinos (camarón y pescado seco de Salina Cruz y "topotillos" de Catemaco, Veracruz) e industrializados, con los que los viajeros extendieron sus vías más allá del contexto regional; se introducían en lugares cada vez más recónditos, cargando cada uno no menos de $50 \mathrm{~kg}$ y caminando semanas enteras. De esta forma llegaron a tocar tierras veracruzanas y chiapanecas. Estas relaciones les permitió visualizar nuevas alternativas de sobrevivencia fuera de su comunidad desde la década de los años veinte.

Por los años treinta tuvo importancia el mineral de La Natividad, Ixtlán, sobre todo como mercado para ir a vender frutas, aves de corral y principalmente huevos de gallina (cuando un huevo costaba en Zoogocho y en los pueblos circunvecinos de 1 a 2 centavos en La Natividad se vendía a 3 centavos, pero las características del producto presentaban dificultades para su traslado, por lo que era limitada la cantidad que ponían al mercado).

Por otro lado, los comerciantes de Mitla, Tlacolula, Díaz Ordaz y otros pueblos de los valles centrales que llegaron a la sierra a principios de siglo (con manta, sal, cera labrada o en bloque, petróleo y mercería que vendían en los mercados semanales o intercambiaban de casa en casa por productos locales como café, 
panela, chile, aguacate, huevos, lazos, hamacas, loza y otras artesanías) fueron imitados y desplazados regionalmente durante los años cuarenta cuando la red comercial se extendió de Oaxaca a Tlacolula (enlace entre los zapotecos y los mixes), Mitla, Ixtlán y Yalálag, cuyos mercados subsidiarios eran los de La Natividad, Talea de Castro, San Juan Yaé, Lalopa, Lachirioag (posteriormente), Villa Alta, Zoogocho, San Pedro Cajonos, Totontepec, Cacalotepec, San Juan Juquila Mixes y Ayutla. ${ }^{11}$ Para estas transacciones los productos se transportaban a lomo de bestias.

Alrededor de 1950 los "viajes" pierden importancia, el comercio en general se canaliza a la ciudad de Oaxaca a través del mercado y las tiendas del lugar. Esta situación es aprovechada por una cadena de intermediarios locales y externos, dueños de las tiendas, quienes funcionan con una alteración incontrolada de precios para incrementar su capital a costa de los lugareños. Los grandes comerciantes de Zoogocho no solamente han alcanzado el poder económico sino también se están consolidando como grupo de poder político, en el sentido de que se imponen y ejercen presión sobre la población, canalizan y dirigen el ejercicio de la autoridad municipal hacia sus propios intereses, y controlan las relaciones con las autoridades o los funcionarios públicos que despachan en la ciudad de Oaxaca.

Por su parte, la autoridad municipal en el "sistema de cargos" se compone de cuatro instancias: a) el presidente con un suplente (regidor primero), un secretario, dos "mayores de vara" y ocho topiles; b) el sindico con un suplente [regidor segundo) y un número indefinido de policías bajo la dirección de cuatro jefes; $c$ ) el alcalde con dos suplentes y un secretario, y d) el tesorero con un suplente (regidor tercero o de hacienda) y dos auxiliares o "cobradores".

Dentro de este sistema entran también los cargos religiosos: un presidente, un tesorero, un secretario, un auxiliar o fiscal, cuatro vocales (conocidos también como regidores o "mayordomos"), dos "jueces de agua" y ocho "topilillos" (niños mandaderos).

Son considerados como cargos mayores o de alto rango los que desempeñan él secretario municipal, los regidores, los tesoreros y los presidentes (tanto municipales como eclesiásticos), el síndico, el alcalde y sus suplentes. Por consiguiente, la mayoría son cargos menores o de bajo rango. Asimismo, existen "cargos extraordinarios", que estando subordinados al "sistema de cargos" no escalan dentro del mismo y son desempeñados por hombres y mujeres: los Comités y las Comisiones de Festejo y de Danza. Por p. 30 .

${ }^{11}$ Véase Onésimo Rîos Hernández [1979), La Sierra de Juárez, s.e., México. 
último, cabe señalar que existe un número reducido de puestos honoríficos, de carácter religioso, sustentados por los "Consejeros Ancianos". ${ }^{12}$

La clasificación de los puestos en la escala jerárquica del "sistema de cargos" se muestra en el cuadro 1. La mayoría de los cargos son de carácter político; asimismo, sólo $24 \%$ del total son de alto rango.

En 1987 los hombres de 15 a 29 años de edad suman un total de 106 elementos, lo que no es suficiente para el desarrollo del "sistema de cargos" en virtud de que, por un lado, son 71 puestos y la norma es que entre uno y otro debe haber un periodo de descanso para cada contribuyente y, por otro, anualmente cierto número de ciudadanos alcanza los puestos mayores y no puede retroceder a ocupar los menores que son los que abundan [76\%]. En términos generales puede establecerse que los cargos de bajo rango los desempeñan hombres de 15 a 34 años de edad y que sólo hay 47 elementos para 54 puestos; los de alto rango los desempeñan los hombres entre 35 y 59 años y tenemos 59 elementos para 17 puestos (véase la gráfica 1). Esto desborda los criterios de edad y estado civil en la designación de los puestos a causa de la fuerte emigración que sufre la población.

\section{El proceso migratorio}

\section{Origenes}

Entre los zoogochenses, durante las tres primeras décadas de nuestro siglo, la cantidad y la calidad de la tierra y la posesión o no de yunta determinaban el monto de los productos obtenidos y, en consecuencia, la estratificación social. En cada ciclo agrícola, la unidad familiar "rica" llegaba a cosechar una cantidad de granos equivalente a tres años de autoconsumo, la "media" a dos y la "pobre" a menos de uno. Esta estratificación estaba muy marcada, existía una insolente explotación interna, los peones eran obligados a cubrir una jornada hasta de 15 horas de trabajo inten-

12 La distinción de anciano no se alcanza sólo por la edad sino también por el cumplimiento de los cargos y servicios encomendados y la capacidad de guiar los asuntos de la comunidad. En la Sierra Norte de Oaxaca en general no existe el Consejo de Ancianos como grupo integrado, por lo que se habla de Consejeros Ancianos. 
CUADRO 1

Zoogocho, Oaxaca: puestos políticos y religiosos según el grado de importancia en el "sistema de cargos" en 1987

\begin{tabular}{lcccccc}
\hline Puestos & Alto rango & $\%$ Bajo rango & \% & Total & $\%$ \\
\hline Políticos & 10 & 16.4 & 51 & 83.6 & 61 & 100.0 \\
Religiosos & 7 & 70.0 & 3 & 30.0 & 10 & 100.0 \\
Total & 17 & 24.0 & 54 & 76.0 & 71 & 100.0 \\
\hline
\end{tabular}

Fuente: Archivo Municipal de Zoogocho, Oaxaca.

GRÁFICA 1

Zoogocho, Daxaca: estructura de la población nativa según los grupos de edad y sexo en 1987

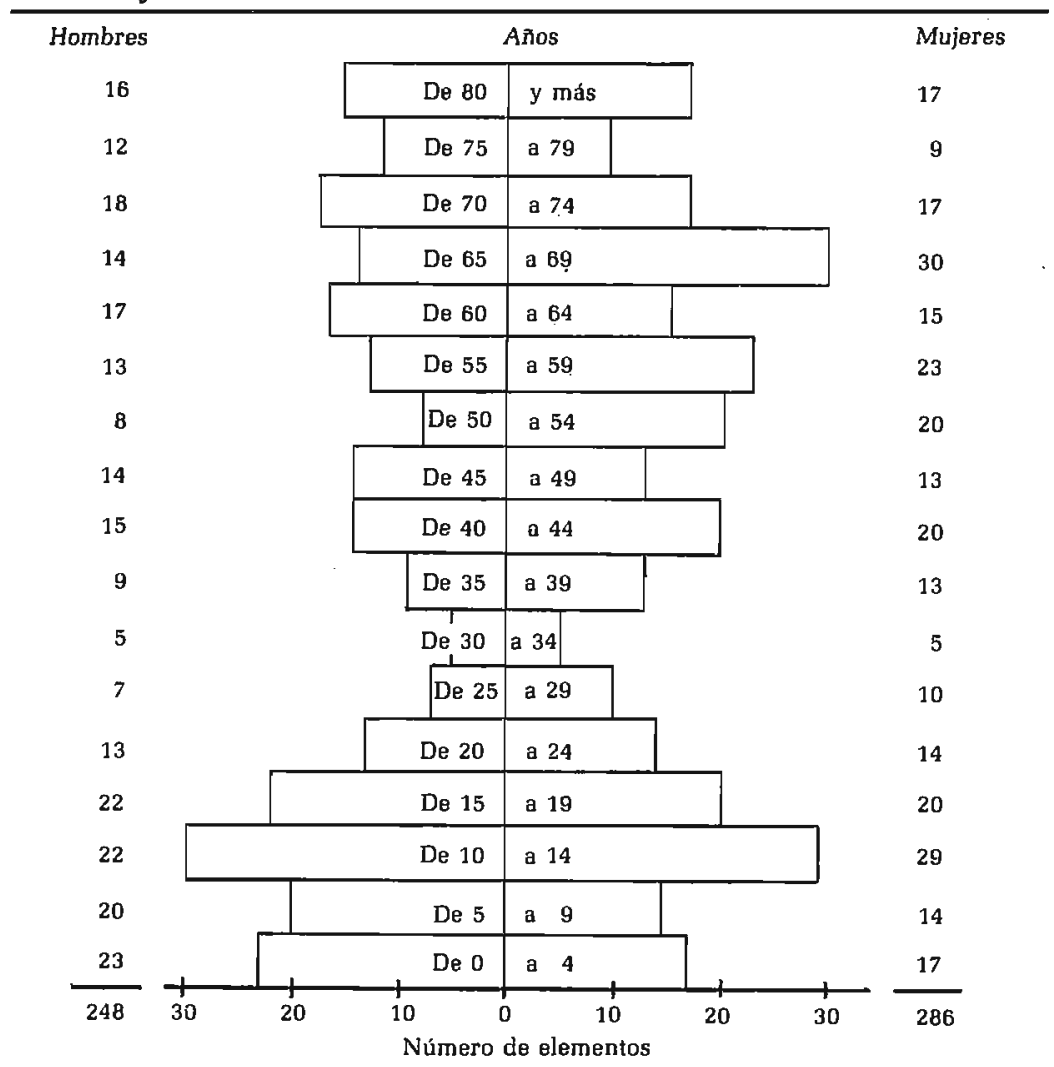

Fuente: Censo Poblacional de Zoogocho, Oaxaca, 1987. 
sivo (bajo la estricta supervisión del patrón) para ganarse un almud de maíz o su equivalente en dinero u otras especies. ${ }^{13}$

Bajo estas circunstancias aparecen los primeros valores económicos y socioculturales urbanos y, en consecuencia, los primeros brotes de emigración con un carácter estacional o temporal, regional y rural-rural, cuando algunos "viajeros", o comerciantes ambulantes, esporádicamente permanecian trabajando fuera de su comunidad, y una inmigración definitiva de unas cinco familias procedentes de las comunidades destruidas en el distrito de Ixtlán alrededor de 1916 a causa de la Revolución. ${ }^{14}$

En la década de los años treinta se dio un proceso de redistribución de los medios de producción en función de diversas relaciones de parentesco, incluyendo el compadrazgo. Los desposeídos y los "campesinos pobres" trabajaron en aparcería o mediería los terrenos de los "ricos" y poseyeron sus yuntas en "compañfa" Esto dio como resultado el desarrollo de una agricultura extensiva que llegó a practicarse en los pueblos circunvecinos. Sin embargo, esto no logró la autosuficiencia económica y la emigración siguió su marcha, con tendencia a hacerse permanente, extrarregional y rural-urbana. Los campesinos se dirigieron por tiempo indefinido a las tierras bajas de Veracruz, al centro minero de La Natividad, Ixtlán, y a la ciudad de Oaxaca.

Los primeros emigrantes fueron jefes de familia que buscaban satisfacer sus necesidades económicas. Empero, el impacto de la sociedad urbana en la comunidad implicaba la necesidad de elementos socioculturales que sólo se podían adquirir en las ciudades, y esto repercutió en la población infantil, iniciándose así una emigración de menores a principios de la década de los veinte.

Los padres de familia vieron en sus hijos la posibilidad de contrarrestar el embate de la sociedad dominante y optaron por enviarlos a la ciudad de Oaxaca para que obtuvieran un ingreso monetario y, sobre todo, aprendieran la lengua española y los valores socioculturales urbanos, para lo cual estuvieron al servicio de gachupines y otras familias "ricas", a quienes llamaban catrines, por un lapso de uno a dos años regularmente. ${ }^{15}$

Este proceso constituyó una verdadera agresión para los me-

13 La medida es de 4.5 litros aproximadamente. En aquel entonces las unidades familiares eran muy extensas y, en algunos hogares, se consumía más de un almud de maíz al día. Nótese el grado de pauperización.

${ }^{14}$ Un número elevado de familias arruinadas emigraron hacia diferentes direcciones y distancias en busca de la sobrevivencia, al desaparecer sus pueblos o ser incendiados y saqueados. Véase Onésimo Hernández (1979:21).

15 Fueron los niños de 12 años y menos los que se integraron a este fenómeno, pues los de más edad no era conveniente separarlos de la unidad productiva. 
MAPA 1

Rutas migratorias de Zoogocho a Oaxaca, México y Estados Unidos

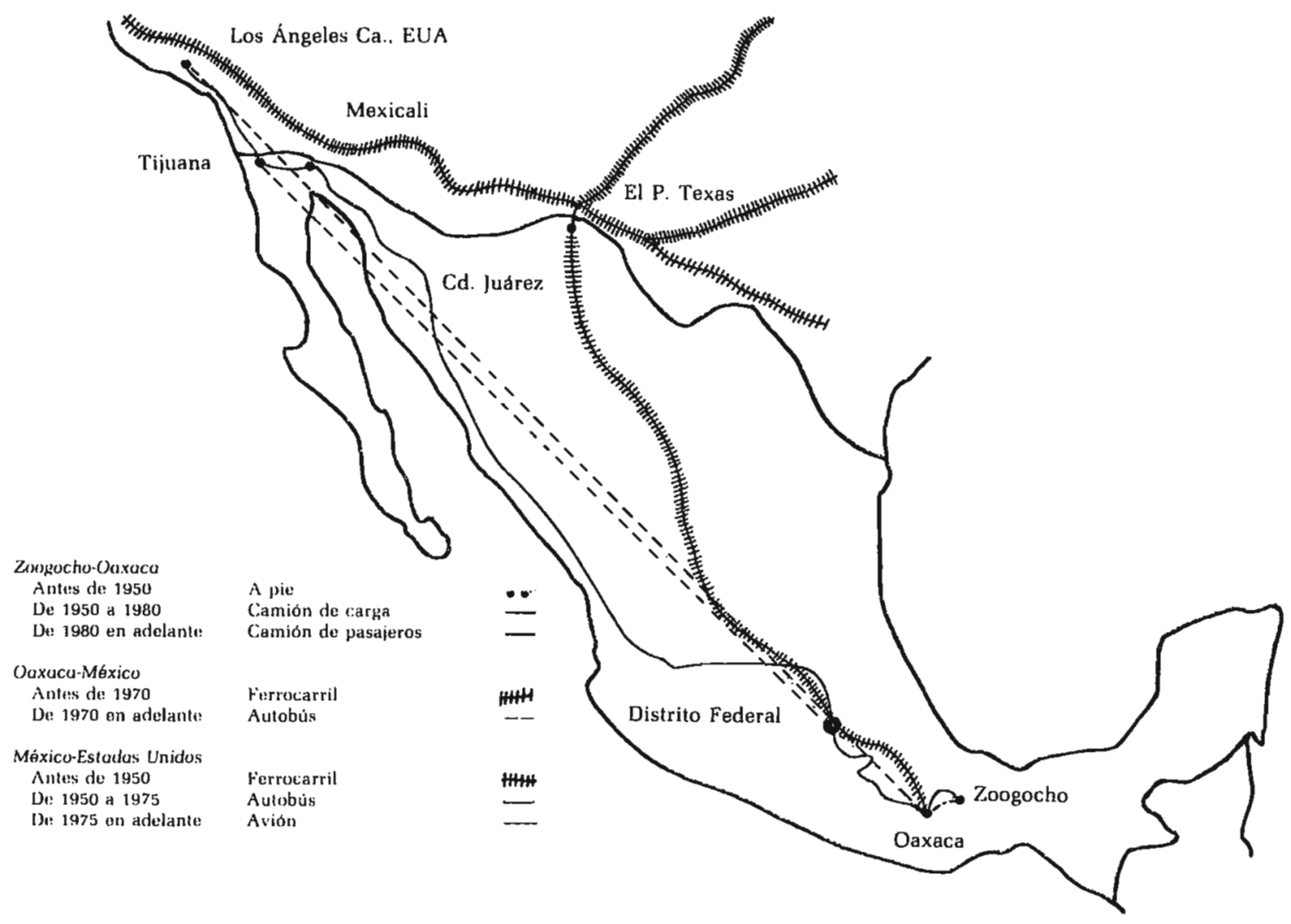


nores. Los que lo vivieron y que aún sobreviven lo recuerdan en los términos siguientes: "mi papá me fue a tirar", "yo lloraba mucho porque no quería quedarme allá", "mi patrón me agarró para no retirarme con mi papá", "yo sufrí mucho", "a mi me maltrataban los hijos de mi patrón", "dormíamos como perros en un petate en la puerta". Asimismo, coinciden en que sólo ganaban lo estrictamente básico en alimentación, vestido y hospedaje y que en el mejor de los casos eran enviados a las escuelas nocturnas.

El objetivo principal de los padres de familia era "preparar" a sus hijos para ya no recurrir a intérpretes [como los maestros rurales que "todo lo resolvían") en los contactos con los jefes políticos y otros representantes del gobierno que los hostilizaban constantemente. Al retornar a su comunidad como portadores de nuevos valores, estos adolescentes fueron reconocidos por su capacidad para afrontar la realidad, oscilando entre la población rural y urbana como medios de contacto, sobre todo los hombres que fueron privilegiados con algunos puestos de alto rango en el "sistema de cargos", como escribanos o secretarios municipales y posteriormente como guías de la comunidad, "bene sin'a" (persona culta o intelectual).

La importancia de este proceso puede notarse en las expresiones de uno de nuestros informantes, ${ }^{16}$ que nos dice que "en aquel entonces ir a Oaxaca era como ir ahora a las grandes Universidades y -agrega- ir a México era como ir al cielo", que alrededor de 1930 solamente Luciano Fernández, Macario Mendoza y Marcelina Mendoza radicaban ya en el Distrito Federal. ${ }^{17}$

Esta migración infantil fue reorientada paulatinamente hacia los internados para jóvenes indígenas que se iban creando en la región: 1936 en Ayutla, Mixe; 1938 en Guelatao, Ixtlán, y 1952 en Zoogocho, Villa Alta. En algunos casos los niños eran enviados a las parroquias de la región, ya que se consideraba un privilegio servir a los sacerdotes, de quienes aprendían el español enfocado a los rezos y a los cantos religiosos. Posteriormente se produjo un fuerte éxodo de menores durante los años sesenta y setenta que se dirigieron a las Escuelas Secundarias y Normales de Maestros, entre los que destacaban las de Reyes Mantecón, ciudad de Oaxa-

\footnotetext{
16 Carlos Modesto Calete, quien migró a la ciudad de Oaxaca desde pequeño y llegó a emplearse en el H. Tribunal Superior de Justicia del Estado de Oaxaca [donde obtuvo la jubilación] y tiene una larga trayectoria como migrante activo para el mejoramiento de su pueblo.

17 Se dice que el primero fue aventurero, ingresó a la Marina y llegó a tocar tierras europeas; el segundo se dedicó a trabajos indefinidos y la tercera (que emigró por haber fracasado en la matanza de puercos) prosperó ampliamente en la elaboración de tortillas en ese lugar de destino.
} 
ca, Tamazulapan, Perote, Veracruz y Distrito Federal. Sin embargo, en la actualidad la población infantil ya no migra hacia los centros de enseñanza, sino espera ansiosamente aventurarse a Los Ángeles, California.

\section{De 1940 a 1990}

La estructura socioeconómica y la migración son dos fenómenos que se relacionan entre sí para determinar los patrones de vida que rigen en Zoogocho. De 1940 a la fecha este proceso se ha manifestado de diversas formas, según las condiciones que han provocado la migración, las características que ésta ha adoptado por lugar de destino y sus consecuencias en la comunidad. Para abordar los aspectos más sobresalientes de esta problemática se parte del cuadro 2.

En términos generales el ritmo que ha adoptado la emigración zoogochense ha ido en ascenso desde 1940, con marcado aceleramiento a partir de 1960 , alcanzando la cifra más alta en 1979, y descendente de 1980 en adelante, como puede apreciarse en la gráfica 2. Sin embargo, su comportamiento ha sido diferente a lo largo de las cinco décadas, por lugar de destino (gráfica 3).

1. Estados Unìdos de Norteamérica. La emigración de los zoogochenses hacia este lugar se produce, a causa de una plaga de langosta que azotó la región en 1941 y a una temporada de sequía en 1943-1944, cuando en 1942 los ya radicados en la ciudad de México fueron enganchados como jornaleros agrícolas a dicho país y en 1943 empezó la salida de Zoogocho; muy impresionante fue el éxodo simultáneo de 84 padres de familia (de 250 aproximadamente) en 1944, apoyados económicamente por la íglesia, a través de la autoridad municipal. Estos migrantes se incorporaron como "braceros" al Programa de Contratación de Trabajadores Mexicanos establecido por Estados Unidos, para subsanar el déficit de mano de obra que tenía en ese momento como consecuencia de su participación en la Segunda Guerra Mundial. ${ }^{18}$

Por el tipo de actividad en oferta [agrícola y construcción o mantenimiento de vías férreas) las contrataciones se centraron exclusivamente en hombres adultos, quienes buscaban los medios de sobrevivencia familiar, lo que hizo de esta migración ruralrural un fenómeno temporal, ya que generalmente retornaban después de 6 o 12 meses.

18 Con varios refrendos y modalidades, el Convenio se extendió del 4 de egosto de 1942 al 31 de diciembre de 1964. 
CUADRO 2

Zoogocho, Oaxaca: emigrantes según el año y el lugar de destino

\begin{tabular}{|c|c|c|c|c|c|c|c|c|}
\hline Año & $\begin{array}{l}\text { Estados } \\
\text { Unidos }\end{array}$ & $\%$ & $\begin{array}{l}\text { Valle de } \\
\text { México }\end{array}$ & $\%$ & $\begin{array}{c}\text { Ciudad de } \\
\text { Oaxaca }\end{array}$ & $\%$ & Totales & $\%$ \\
\hline $1940-1949$ & 44 & 62.9 & 15 & 21.4 & 11 & 15.7 & 70 & 100.0 \\
\hline $1950-1959$ & 9 & 12.8 & 51 & 71.8 & 11 & 15.4 & 71 & 100.0 \\
\hline $1960-1969$ & 53 & 30.0 & 107 & 60.0 & 17 & 9.0 & 177 & 100.0 \\
\hline $1970-1979$ & 158 & 55.3 & 83 & 29.0 & 45 & 15.7 & 286 & 100.0 \\
\hline $1980-1987$ & 72 & 48.3 & 46 & 30.9 & 31 & 20.8 & 149 & 100.0 \\
\hline Totales & 336 & 44.6 & 302 & 40.1 & 115 & 15.3 & 753 & 100.0 \\
\hline
\end{tabular}

Fuente: Censo Poblacional de Zoogocho, Oaxaca, 1987.

A partir de 1950, a raíz de las restricciones del Convenio sobre Braceros, los migrantes tienden a buscar fuentes de trabajo en los centros urbanos, como jardineros, y se produce una disminución cuantitativa del proceso, aun cuando empieza la participación de la mujer. Sin embargo, para esta migración rural-urbana, alrededor de 1960 se inicia el éxodo de hombres y mujeres, mayoritaria-

GRÁFICA 2 GRÁFICA 3

Zoogocho, Daxaca: emigración de 1940 a 1987
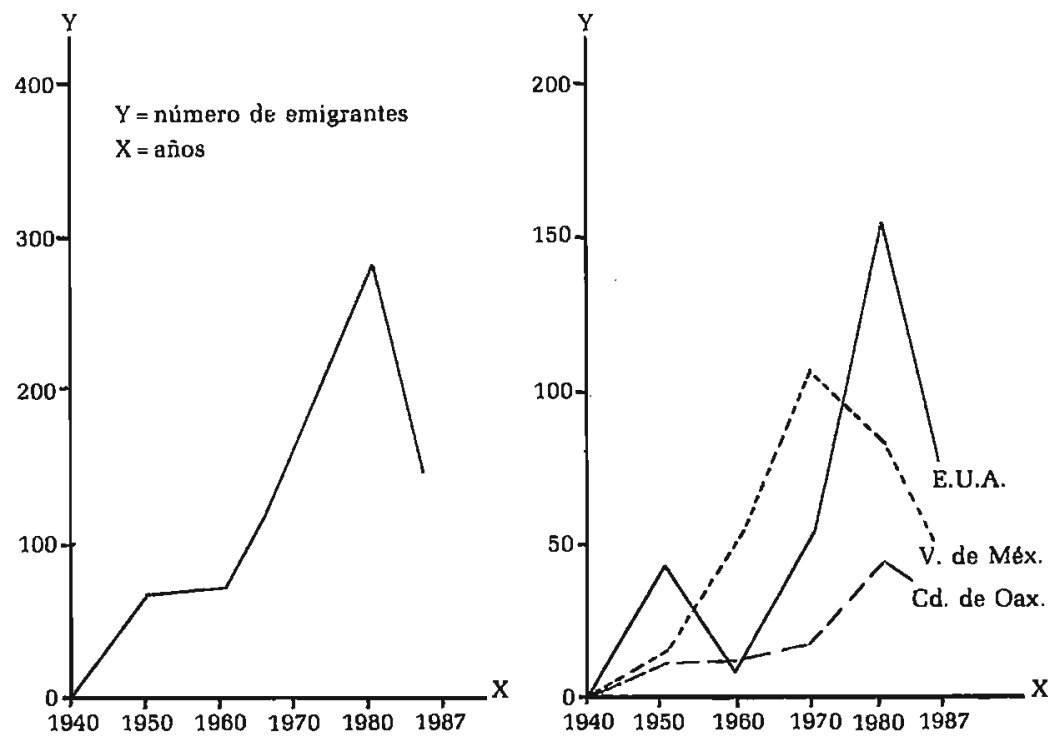

Fuente: Censo Poblacional de Zoogocho, Oaxaca, 1987. 
mente jóvenes y solteros, quienes aspiran a mejorar su situación económica y a alcanzar un grado de prestigio en nivel individual y familiar dentro de la comunidad.

Las restricciones del Convenio sobre Braceros y el impacto de la crisis en la región dan lugar a que muchos migrantes crucen la frontera ilegalmente antes de 1965, para permanecer en aquel país por tiempo indefinido. Con la saturación en las actividades agrícolas, estos "indocumentados" se ven obligados a buscar fuentes de trabajo en las ciudades, en donde es más fácil librarse de la deportación. Durante los años sesenta y setenta la mayoría se empleó en las fábricas de ropa en Los Ángeles, California. Sin embargo, dada la incontrolada concentración es necesario buscar nuevas fuentes de trabajo y éstas se canalizan hacia los restaurantes, como lavaplatos, meseros y cocineros, los hoteles y posteriormente las tintorerías en el caso de los hombres, y las mujeres en los servicios domésticos, incluso de los mismos migrantes.

Las distintas fuentes de trabajo garantizan ocupación a nuevos migrantes, quienes apoyados por sus familiares y amigos aseguran su traslado a esa ciudad durante los años setenta. Empero, a partir de 1980 se presenta un palpable decremento en este proceso, debido a los múltiples y variados escollos para incorporarse a la estructura ocupacional, situación que culmina con el cierre de oportunidades de empleo a nuevos indocumentados por la promulgación de la Ley Simpson-Rodino el 6 de noviembre de 1986, en torno a la cual reina un ambiente de inseguridad entre los $\mathrm{mi}$ grantes y pobladores de Zoogocho. De ahí que de 1980 a 1986 solamente 71 zoogochenses se dirigen a Los Ángeles, California y en 1987 únicamente una adolescente migra a esta ciudad. Sin embargo, después de que la Simpson-Rodino entra en vigor y se aplica prácticamente a partir del 5 de mayo de 1987 la incertidumbre se va disipando y, en consecuencia, la emigración se reanima en los años posteriores. Los migrantes legalizados por la misma ley tienen facilidades de acaparar fuentes de trabajo, caso concreto las jardinerías, con las que ocupan a sus coterráneos que van llegando como nuevos indocumentados, ejerciendo sobre ellos una fuerte explotación.

Actualmente, $10 \%$ de los zoogochenses radicados en Estados Unidos se ocupa en actividades agrícolas (trabajando de sol a sol, y su salario varía entre 15 a 35 dólares al día, según experiencia y tipo de contratista); $40 \%$ en los restaurantes, hoteles, tintorerías y en las labores domésticas, y trabaja 40 horas a la semana (el sala. rio mínimo es de 4.25 dólares por hora y hay quienes ya logran ganar hasta 15 dólares por hora) y $50 \%$ en las fábricas de ropa, en donde se gana a destajo [desde 3 hasta 20 centavos de dólar por 
pieza según experiencia). En este proceso son determinantes los lazos fraternales que los une tanto para auxiliarlos en los costos de traslado como para ubicarlos en la estructura ocupacional. ${ }^{19}$

2. Valle de México. A mediados de la década de los cuarenta empezó a crecer significativamente la concentración de zoogochenses de ambos sexos (jóvenes y solteros en su mayoría) en la ciudad de México, con carácter permanente. Estos migrantes, además de la superación económica, aspiraban integrarse a la vida urbana (adoptar la lengua nacional y los patrones de vida citadinos) el tiempo que fuera necesario.

La no calificación de su mano de obra condujo a las mujeres al servicio doméstico y a los hombres al subempleo, hasta que estos últimos empezaron a practicar la peluquería al grado de llegar a convertirla en la fuente de trabajo más importante alrededor de 1960 , y posteriormente empezaron a ingresar a la Secretaría de la Defensa Nacional, la Secretaría de Comunicaciones y Transportes y al Departamento del Distrito Federal. Por su parte, las mujeres empezaron a ingresar en diversas fábricas y después de 1970 algunas en la Secretaría de Comunicaciones y Transportes, y otras al casarse dejaron de trabajar.

Durante los años cincuenta y sesenta los migrantes se apoyaron en sus antecesores, vivieron con sus parientes $\mathrm{o}$ amigos mientras aprendían la peluquerfa o conseguían un empleo. Esto y la migración internacional definieron las características actuales de la concentración zoogochense en el valle de México. Los que no estaban decididos a permanecer en el Distrito Federal se fueron de "mojados" a Los Ángeles, California y los que optaron por establecerse definitivamente en la ciudad de México, o su área circundante (lógicamente los que ya tenían una fuente de trabajo segura) empezaron a comprar lotes. Para 1975 , con excepción de los pocos que adquirieron terrenos o casas en el Distrito Federal, en el valle de Aragón y los que no pudieron hacerlo, los zoogochenses estaban ya distribuidos como propietarios en la Ciudad Nezahualcóyotl. ${ }^{20}$

A partir de 1970 es cada vez menor el número de zoogochenses que se dirigen a este lugar, debido a la falta de fuentes de traba-

19 Al finalizar 1989, el pasaje de Zoogocho a la ciudad de Oaxaca y de ésta a Tijuana es de 7500 y 495377 pesos respectivamente, y el "coyotaje" fluctúa entre 780000 y 1500000 pesos correspondientes a 300 y 500 dólares respectivamente.

20 Véase Donato Ramos Pioquinto, "La comunidad indígena de Zoogocho: 1940-1980". en México Indígena (1986: 40). 
jo y a la importancia de la migración a Los Ángeles, California. Actualmente ya no emigran al valle de México.

3. Ciudad de Oaxaca. Durante la década de los cuarenta se produce la decadencia de la migración infantil obligatoria de Zoogocho a la capital del estado, y paralelamente se desarrolla una migración permanente, cuyos agentes eran generalmente jóvenes de ambos sexos, quienes se ocuparon en el trabajo doméstico y posteriormente en el pequeño comercio. Durante los años sesenta el fenómeno empezó a ascender notablemente cuando por un lado, los migrantes empezaron a colocarse en los empleos de gobierno y, por otro, se iba concentrando en esta ciudad una población estudiantil cada vez mayor.

A partir de 1980 es amplia la participación de profesores de enseñanza primaria y secundaria y otros profesionistas en este proceso. Sin embargo, es mayor la deserción escolar que se está produciendo en los diversos niveles educativos; los adolescentes y jóvenes migran preferentemente hacia Estados Unidos. Esta situación se explica por el total descuido de la enseñanza emanado del movimiento magisterial (que ha sido permanente en el estado de Oaxaca desde hace diez años aproximadamente, como consecuencia de la política educativa oficial); los altos costos para lograr una formación profesional, y la falta de campo de acción; incluso hay profesores normalistas y otros profesionistas que se han desplazado temporal o permanentemente hacia Los Ángeles, California, por no haberse podido ubicar en situaciones favorables de remuneración. De ahí que es notorio el descenso en la trayectoria migratoria a la ciudad de Oaxaca durante los años ochenta.

Con todo lo anterior se observa que Zoogocho está afectado por un fuerte proceso dr emigración. Sin embargo, en la configuración de su población y en su dinámica socioeconómica y cultural también es importante el otro aspecto del fenómeno, la inmigración, lo que se demuestra a partír del cuadro 3 .

En este cuadro se observa que la población nativa presenta un

CUADRO 3

Zoogocho, Oaxaca: población nativa, inmigrante y total y cambio porcentual entre 1940 y 1987

\begin{tabular}{lrrr}
\hline Población & 1940 & 1987 & \multicolumn{1}{c}{$\%$} \\
\hline Nativos & 1107 & 534 & -51.76 \\
Inmigrantes & 18 & 210 & 1066.66 \\
Total & 1125 & 744 & -33.87 \\
\hline \multicolumn{2}{c}{ Fuentes: Censo General de Población y Vivienda, 1940; Archivo Municipal y Censo Po- } \\
blacional de Zoogocho, 1987.
\end{tabular}


decremento de $51.7 \%$, mientras que la inmigrante se incrementa en $1066.66 \%$, lo que determina que el crecimiento de la población total sea de $-33.87 \%$ en el periodo abarcado.

Del grupo de inmigrantes, solamente 15 personas se dedican a la economía campesina, 3 al comercio y la gran mayoría desarrolla funciones que impulsan la castellanización y la difusión de las normas socioculturales urbanas.

Alrededor de 1940 se establece la oficina de Recaudación de Rentas con un empleado; en 1952 se instituye el Internado para Jóvenes Indígenas "Lázaro Cárdenas", hoy CIS núm. 8, con 150 alumnos y 23 empleados (personal docente y administrativo); en 1967 el número de profesores en la Escuela Primaria Rural Federal "20 de Noviembre" pasa de 3 a 7; en 1970 se instala la Comisión Federal de Electricidad con 4 empleados, en 1975 se establece la Administración de Telégrafos con 2; en 1979 se funda la Unidad Médica IMSs-Coplamar con 3 empleados, en 1980 se instaura la Administración de Correos con 2 y actualmente se está creando la Escuela Secundaria Técnica núm. 164.

Estos inmigrantes constituyen el $28.23 \%$ de la población de Zoogocho en 1987, lo que tiene un peso significativo en las transformaciones socioculturales de la comunidad. Sin embargo, son más evidentes los cambios generados por la emigración.

\section{Migración y unidad familiar}

La relación entre los pobladores y migrantes de Zoogocho está en función de las características del proceso migratorio. Durante los años cuarenta, cuando la catastrófica situación en la comunidad demandaba apoyo económico, los niños y jóvenes en la ciudad de Oaxaca, los braceros en Estados Unidos y las primeras generaciones de migrantes permanentes en el Distrito Federal, tenían como objetivo fundamental aportar recursos monetarios para la sobrevivencia de su unidad familiar, incluso los braceros llegaron a enviar su salario íntegro. Las remesas fueron empleadas para satisfacer las necesidades elementales como la alimentación y el vestido.

En el plano sociocultural, los que habian participado en la migración infantil a la ciudad de Oaxaca adquirieron un alto grado de prestigio en la comunidad, llegando a ocupar puestos clave en el "sistema de cargos" y a dirigir los asuntos de la comunidad. Los ex braceros ascendieron en la estratificación social, lo que motivó a nuevos emigrantes. Esta situación fue reforzada con las visitas (en las fiestas) de los migrantes permanentes en la ciudad de Méxi- 
co, quienes mostraban abiertamente los valores urbanos ya adquiridos: la lengua, el vestido y el calzado.

Durante los años cincuenta y sesenta, a mayor emigración menor fuerza de trabajo dentro de la comunidad y mayor ingreso monetario. Los migrantes, sin la presión de una situación desastrosa, tendieron a auxiliar la economía campesina y mejorar los niveles de vida de su unidad familiar, en especial con la construcción de casas de adobe (típicas) que sustituyeron los llamados "ranchos".

Por otra parte, empezó una fuerte difusión de los valores socioculturales urbanos, a través de las visitas a la comunidad o por medio de cartas desde la ciudad de Oaxaca, el Distrito Federal y Estados Unidos para invitar a sus familiares a integrarse al proceso migratorio, garantizándoles trabajo y hospedaje.

Aun cuando la migración logra significativos cambios en la estructura socioeconómica, el relieve y el clima ya no garantizan la productividad agrícola, por lo que, a partir de 1970 se tiende cada vez más a "buscar el futuro" por la ruta de la emigración, y desde el lugar de destino apoyar a la unidad familiar en forma directa y ya no a través de la agricultura de subsistencia. En 1987 $13.1 \%$ de las unidades familiares vive exclusivamente de la aportación de sus migrantes. 21

En cuanto a la canalización de las aportaciones no se emprenden gastos de inversión sino se ocupan en alimentación, vestido y vivienda. Alrededor de 1970 se inicia un proceso de construcción de casas de concreto con características urbanas. Paralelamente se tiende a despilfarrar en el consumo de productos industrializados y se desarrolla una apatía o antipatía hacia la economía campesina que culmina con el ocio y la vagancia, en los jóvenes y adolescentes principalmente, como lo confirman las palabras del señor Aurelio Morales Mendoza:

Yo me acuerdo muy bien que hasta hace unos años mucha gente andaba descalza y con ropa remendada, se trabajaba desde que amanecía hasta que anochecía y no habia casas de concreto, pero ahora ya hay puros flojos, porque ya hay mucho dinero de los gringos, de ahí también vienen sus tenis y su ropa, casi todas las casas ya son de concreto y los campos olvidados... ya no hay pobreza como antes. ${ }^{22}$

\footnotetext{
21 No existe una cantidad típica ni una frecuencia regular de las remisiones, por lo que no es posible cuantificarlas. Sin embargo, en cuanto a sus efectos tenemos, por ejemplo, que de 1982 a 1987 el número de familias que viven básicamente de la agricultura disminuye de 140 a 96 , en cambio para el comercio aumenta de 9 a 29.

22 Activo campesino zoogochense que en 1987 tenía 92 años.
} 
Los cambios generados por el dinero proveniente de Estados Unidos y de la migración en general en los niveles de vida transforman también la estructura sociocultural, el consumo, por ejemplo, de productos industrializados ya no responde a los rituales autóctonos. Asimismo, implican modificaciones sustanciales en la organización social en su conjunto.

\section{Migración y "sistema de cargos"}

La participación de los emigrantes es importante económica y socioculturalmente; además de la contribución al ingreso familiar, existe la preocupación por contribuir al desarrollo de su pueblo en pro de su identidad, lo que implica una prolongación de la comunidad más allá de sus límites territoriales.

La relación de estos migrantes con la comunidad se convierte en una necesidad; conocen su normatividad y sienten que deben participar moral y socioeconómicamente en ella ". . . la responsabilidad tremenda de servir a Zoogocho. En dondequiera que nos encontremos ya sea en Oaxaca, en México o en Los Ángeles pensamos en Zoogocho. Los problemas del pueblo son nuestro común denominador y ésa es nuestra bandera de lucha". ${ }^{23}$ Su participación en el "sistema de cargos" mantiene vivos los lazos con el pueblo, relación que se convierte en una constante presión, aun cuando toda la familia haya migrado.

La transformación de la comunidad acorde con las exigencias de la época está en función de la contribución de los migrantes en sus distintas formas y niveles. Desde antes de 1940 los radicados en la ciudad de México aportaron algunos valores materiales; en 1945 los braceros enviaron sus primeras cuotas (25 pesos mexicanos cada uno) y los residentes en la ciudad de Oaxaca empezaron a fungir como elementos clave para canalizar los asuntos oficiales y particulares de Zoogocho en el complejo sistema urbano desde los años cuarenta.

Para coordinar sus actividades y coadyuvar al progreso y desarrollo de su comunidad los migrantes fundaron en 1951 la Unión Fraternal Zoogochense en México, en 1969 la Unión Social Zoogochense en Los Ángeles, California y en 1974 el Frente Unificador Zoogochense "José Jacinto de Santiago" en Oaxaca. Cada una de estas organizaciones desempeña determinadas funciones según la sede y el número de integrantes: la Unión Fraternal Zoo-

23 Véase México Indígena (1986: 43). 
gochense desde siempre ha tenìlo una función económica y gestora lenvio anual de dinero y trámites en las dependencias federales para adquisición de servicios públicos en la comunidad); la Unión Social Zoogochense se limita a la función económica, y es el organismo que envía mayor cantidad de dinero anualmente, y el Frente Unificador Zoogochense es de carácter económico débil, pero de incomparable función gestora [sus constantes relaciones con la autoridad municipal de Zoogocho y las "autoridades superiores" son determinantes). De esta forma es incuestionable la labor colectiva entre los pobladores y los migrantes.

En 1940, con una población total de 1125 habitantes y un número insignificante de migrantes, Zoogocho tenfa suficiente mano de obra pero carecia de recursos financieros para emprender un trabajo sobresaliente. El "tequio" se limitaba a pequeñas actividades y no se vislumbraba ninguna posibilidad de lograr el establecimiento de algún servicio público. A partir de 1945 la combinación del "tequio" con la aportación económica de los braceros hizo posible la construcción de las instalaciones escolares, que posteriormente fueron ocupadas por el Internado para Jóvenes Indígenas "Lázaro Cárdenas", logrado en 1952 gracias a la participación de los zoogochenses radicados en la ciudad de México. De esta forma se inició un proceso de labor colectiva que se ha mantenido hasta hoy.

Durante los años sesenta se llegó al acuerdo entre los pobladores y emigrantes de que estos últimos no participarfan en el "sistema de cargos" que rige en Zoogocho, aun cuando pertenecieran a alguna de las organizaciones formadas en los lugares de destino. Sin embargo, este acuerdo se ha alterado paulatinamente y alrededor de 1970 empezaron a designar cargos a los emigrantes.

La no aceptación de los cargos implica fuertes censuras y pérdida de prestigio o posición social, por lo que fueron aceptados en su mayoría, y fueron desempeñados en un primer momento por los familiares, en detrimento de su economía y su prestigio cuando los que ya habían superado los cargos menores vuelven a ellos por sus emigrantes. Posteriormente se contrataron otras personas para ello. Sin embargo, esto ha sido cada vez más difícil debido a la constante reducción de la población y a la agudización de la crisis económica del país. Alrededor de 1980, los migrantes ofrecen determinada cantidad de dinero al municipio en lugar de desempeñar los puestos, pero esto no es aceptado y provoca un mayor rechazo a la participación en el "sistema de cargos", y una mayor preocupación por plantear alternativas que no afecten la unidad pobladores-emigrantes. En consecuencia, los pobladores deciden asignarles cargos de alto rango a los emigrantes próceres 
CUADRO 4

Zoogocho, Oaxaca: "mayordomos" según el lugar de residencia y el año

\begin{tabular}{lccccccr}
\hline \multicolumn{1}{c}{ Residencia } & 1985 & 1986 & 1987 & 1988 & 1989 & 1990 & Total \\
\hline Los Ángeles, Ca. & 1 & 1 & 0 & 1 & 2 & 0 & 5 \\
Valle de México & 2 & 0 & 2 & 3 & 2 & 2 & 11 \\
Ciudad de Oaxaca & 0 & 0 & 1 & 0 & 0 & 0 & 1 \\
Zoogocho, Oaxaca & 1 & 3 & 1 & 0 & 0 & 2 & 7 \\
Total & 4 & 4 & 4 & 4 & 4 & 4 & 24 \\
\hline
\end{tabular}

Fuente: Archivo Municipal de Zoogocho, 1987.

de las organizaciones respectivas, ${ }^{24}$ destacando las "mayordomías" como se muestra en el cuadro 4.

De los 24 ciudadanos que han desempeñado las "mayordomías" en los últimos sies años, 17 son emigrantes: 11 residentes en el valle de México, en donde hay muchos de edad avanzada que se concentraron ahí desde los años cuarenta y entre los que se está dando un proceso de jubilación; 5 en Los Ángeles, California, en donde reside gente que migró después de 1960 y uno en la ciudad de Oaxaca, en donde se han concentrado estudiantes, profesionistas y otros que migraron también después de 1960 principalmente.

En el plano político los cargos de alto rango se centran en los tres regidores, el síndico y el presidente. De ahí que para el periodo 1987-1988, todos estos puestos fueron conferidos a los residentes en Los Ángeles, California, de los cuales sólo uno se opuso (a la regiduría] y los otros cuatro retornaron para tomar posesión el 15 de septiembre de 1987. Estos puestos demandan forzosamente la participación directa de los elegidos, no se aceptan personas contratadas ni familiares, lo que implica un retorno obligatorio de los migrantes, por lo menos durante el año en funciones.

Bajo estas circunstancias, la Unión Social Zoogochense en Los Ángeles, California plantea aumentar la cuota anual que se envía a Zoogocho a cambio de que los migrantes en ese lugar estén exentos de los cargos; la Unión Fraternal Zoogochense, A.C., en el valle de México solicita que se reafirme el acuerdo que exenta a sus miembros activos de los cargos, y el Frente Unificador Zoogochense en la ciudad de Oaxaca suspende su aportación al pueblo desde 1983 y en 1986 dirige a Zoogocho una protesta, en términos legales, en contra de los nombramientos a los migrantes. Sin embargo, no se ha encontrado la alternativa de solución, ya que, por un lado, la toma de decisiones se sigue dando desde Zoo-

${ }^{24}$ A través de las organizaciones es más fácil vigilar, clasificar y controlar a los migrantes desde la comunidad de origen. 
CUADRO 5

Zoogocho, Daxaca: emigrantes según el lugar de destino y la posición sobre la participación en el "sistema de cargos" en 1987

\begin{tabular}{lcccccc}
\hline \multicolumn{1}{c}{$\begin{array}{c}\text { Lugar de } \\
\text { destino }\end{array}$} & $\begin{array}{c}\text { Está de } \\
\text { acuerdo }\end{array}$ & $\%$ & $\begin{array}{c}\text { No está de } \\
\text { acuerdo }\end{array}$ & $\%$ & Total & $\%$ \\
\hline Valle de México & 14 & 31.1 & 31 & 68.9 & 45 & 100.0 \\
Ciudad de Oaxaca & 23 & 33.3 & 46 & 66.7 & 69 & 100.0 \\
Total & 37 & 32.5 & 77 & 67.5 & 114 & 100.0 \\
\hline
\end{tabular}

Fuente: encuesta aplicada en el valle de México y ciudad de Oaxaca.

gocho ${ }^{25} \mathrm{y}$, por otro, en el seno de cada organización los migrantes se clasifican según los que están de acuerdo y los que no lo están para desempeñar los cargos. Esto se muestra en el cuadro 5 .

De los 114 migrantes de sexo masculino de 20 a 70 años de edad, $37(32.5 \%)$ están de acuerdo en que se les asignen cargos porque desean desempeñarlos para adquirir posición social en la comunidad, o cumplir una promesa emanada de su situación migratoria: "a veces cruza uno la frontera con problemas muy difíciles, entonces se acuerda uno del santo patrón y le promete servirle todo con tal de salir bien".

En cuanto a los puestos deseados se prefiere los de alto rango; sólo cuatro de los 37 "voluntarios" no tienen preferencia. Sin embargo, son los pobladores quienes designan los cargos, según los mecanismos internos de la comunidad. ${ }^{26}$

La integración de los migrantes al "sistema de cargos" es importante para la sobrevivencia de la comunidad ante el embate de la sociedad dominante en los últimos años. De ahí que, la dinámica socioeconómica de Zoogocho dependa de la influencia que ejerce la emigración tanto en la organización familiar como en la comunitaria. De esta forma, la migración se presenta, por un lado, como un elemento de reproducción de las estructuras comunitarias en su articulación con la sociedad dominante y, por otro, como un elemento de transformación o configuración de estas estructuras, ". . ha cambiado mucho, los que regresan a la fiesta

25 Para la comunidad, los acuerdos se constituyen principalmente por la asamblea general con base en las costumbres o normes locales, en donde el proceso legal sólo opera para la formalización de documentos.

${ }^{26}$ Ante la constante reducción del número de contribuyentes se han desbordado los criterios de edad y estado cjvil para la selección (cabe mencionar que de los ocho "topilillos" que estuvieron en funciones en 1990, cuatro son bebés menores de dos años, cuyas actividades fueron desempeñadas por sus hermanos, o sus padres); los cargos menores han sido reajustados (reducción del número de policías y supresión de algunos comités) y se ha reducido a un año el descanso entre un cargo y otro (se dan casos de designación continua). 
nada más vienen a divertirse y no van a misa, ya no adoran a los santos como se debe". Asimismo, los servicios de los consejeros ancianos son sustituidos en gran medida por los familiares y amigos de los "mayordomos" emigrantes, la "guelaguetza" en productos ha perdido importancia por la circulación de dinero en efectivo en la organización de las "mayordomías", y el consumo de los productos locales o regionales se minimiza cada vez más ante el embate del consumismo de mercancías propiamente dicho.

Con lo expuesto es palpable que la migración responde progresivamente a las necesidades de participar en el mercado capitalista de trabajo y bienes de consumo. En el medio rural, donde se produce la emigración y, en consecuencia, el flujo de dinero y valores socioculturales urbanos, los patrones de vida del campesino-indígena se transforman sustancialmente.

\section{Conclusiones}

Las comunidades rurales en general se encuentran en estrecha vinculación con la sociedad dominante, por lo tanto se debe partir de esta relación para delimitar la problemática que de ellas se quiera abordar, estableciendo los ejes explicativos en función de los fenómenos locales y externos que se unifican en un solo proceso, pero que en determinados espacios geográficos y temporales unos sobresalen, aunque en última instancia los externos son los que se imponen y provocan o aceleran desequilibrios que conducen a las comunidades a una crisis que las transforma y, por ende, las subyuga paulatinamente a la sociedad dominante.

Los límites entre lo propio y lo impuesto, así como lo estructural y lo coyuntural se desvanecen en la naturaleza misma del objeto de estudio, es decir, sus dimensiones se ubican en diversos grados. De ahí que, su inserción en un contexto mayor no es cuestión de terminologias o tipologías. Independientemente de que se trate de una o de varias comunidades y de que se hable de estudio de caso o regional, lo importante es determinar la participación y el alcance del fenómeno, en su relación con otros, en la conformación de un proceso cada vez más amplio, cuyos periodos no se establecen al margen de la realidad.

Desde la óptica anterior se ha detectado que la comunidad campesino-indígena de Zoogocho, Oaxaca, en su contacto con la sociedad dominante, ha sufrido cambios sustanciales en su estructura socioeconómica, cuyas manifestaciones se relacionan directamente con el fenómeno de la migración.

Durante las dos primeras décadas del siglo xx, la vida econó- 
mica y sociocultural de Zoogocho dependía fundamentalmente de sus factores físico-naturales y de las instituciones comunitarias. La agricultura de temporal, las artesanías y el trueque de productos, así como el "sistema de cargos" reproducían las condiciones de vida en la instancia familiar y colectiva. La estratificación social se basaba principalmente en la extensión y productividad de los terrenos, los dueños de las parcelas menos accidentadas y mejor ubicadas con respecto a los pozos o arroyos eran los más prósperos. De ahí que las condiciones locales eran dominantes y determinantes; las relaciones con los pueblos circunvecinos no afectaban en esencia a la comunidad. La influencia del exterior, a través de los jefes políticos principalmente, fue reforzada coyunturalmente en 1916 por el refugio de las víctimas de la Revolución, quienes poseían valores socioculturales upbanos.

Posteriormente, el impacto del exterior sobre la comunidad de Zoogocho fue aumentando a través del comercio, por un lado (la presencia de los productos provenientes de los centros urbanos era cada vez mayor) y por otro, por los comerciantes locales que iban extendiendo sus redes hacia lugares más retirados. Esto implicaba un intercambio desigual entre los productos externos y los internos y una diferenciación entre los valores socioculturales, en detrimento de los autóctonos y, en consecuencia, la emigración.

Por los años veinte, algunos zoogochenses se fueron a trabajar por uno o dos ciclos agrícolas a las tierras del distrito de Choapan o del estado de Veracruz, para mejorar la situación económica de su familia y otros, alrededor de 1930 , empezaron a perfilarse hacia las ciudades, destacando el envío forzoso de menores a la capital del estado.

Es de notar que la influencia de los maestros rurales (portadores de valores socioculturales urbanos) en la comunidad tuvo un peso considerable, al grado de llegar a cancelar definitivamente la "mayordomía" de la fiesta patronal a cargo de la autoridad municipal, cuando en 1935 llegó a la presidencia el profesor Román Cervantes y Cristóbal, y en consecuencia se formó la Comisión de Festejos.

Bajo estas circunstancias, la dinámica socioeconómica de Zoogocho no había sufrido cambios radicales, es decir, todavía predominaban los factores internos sobre los externos. Jaa economía campesina y el "sistema de cargos" seguían cumpliendo su función y la estratificación social se basaba aún en la acumulación de granos. El impacto de la sociedad dominante era progresivo, pero paulatino hasta que en 1941 y en 1943 causas externas (plagas y sequía respectivamente) alteraron los factores físiconaturales en detrimento de la economía campesina, lo que coinci- 
dió con otro momento de coyuntura, la contratación de braceros por parte de Estados Unidos de Norteamérica. Por consiguiente, se produce una emigración masiva hacia dicho país que, independientemente de su corta duración (contratos por seis meses), constituye el antecedente de una permanente emigración internacional.

Durante los años cuarenta, la economía familiar empieza a recibir los beneficios de la emigración, y en 1945 la autoridad municipal recibe la primera aportación económica de los emigrantes braceros. ${ }^{27}$

Otro momento crucial, y quizá el más importante en la historia de la comunidad, fue el hecho de que en 1951 se organizan formalmente los migrantes en la ciudad de México para apoyar económica y socioculturalmente a su pueblo. A partir de este año empieza un proceso de "modernización" permanente que consiste, por un lado, en la construcción de obras materiales con características urbanas $\mathrm{y}$, por otro, en la adquisición de instituciones oficiales y, en consecuencia, la inmigración de gente urbana o urbanizada. Por consiguiente, los factores externos empiezan a predominar en la dinámica socioeconómica de la comunidad. Asimismo, el radio y la red de caminos se extienden cada vez más y en ese mismo año llega el primer camión de carga a Zoogocho.

A raiz de lo anterior, se produce una progresiva emigración de jóvenes solteros de ambos sexos que buscan satisfacer sus necesidades económicas y socioculturales emanadas del embate de la sociedad dominante. Durante los años sesenta y setenta aumenta el número de adolescentes que emigran para estudiar. Sin embargo, esto último disminuye antes de 1980, debido a la crisis económica del país y de la importancia que adquiere la emigración internacional.

"Sufrir" el impacto de la sociedad dominante es "sufrir" su crisis; la fuerte inflación demanda recursos que no se consiguen localmente, ya que tampoco la economía campesina brinda resultados favorables, lo que implica una agudización de la emigración, рего no como elemento de refuncionalización de lo autóctono sino como estrategia de sobrevivencia ante el dominio de lo externo. En 1987 solamente 19 unidades familiares [10.8\% de 176] no tenía emigrantes ni elementos con historia migratoria.

El flujo de dinero emanado de la emigración ha logrado cambios en la estratificación social, "antes tenfamos que vender nuestras cosas y vendernos a los ricos, pero eso ya se acabó, la gente ya tiene dinero y cuando tiene un compromiso le pide a sus fami-

${ }^{27}$ Cabe mencionar que con la migración internacional se establecen algunas tiendas y cobra mayor importancia la compra-venta de café. 
liares que están en Los Ángeles". Sin embargo, de este proceso emerge un estrato social integrado por los comerciantes, quienes se fortalecen cada vez más gracias a la apropiación cotidiana de estos ingresos. Por lo tanto, los más beneficiados de la emigración son los comerciantes, ya que llega a sus manos dinero de todas las familias de Zoogocho y de los pueblos circunvecinos. Actualmente, este estrato social ya ejerce una fuerte influencia en los asuntos políticos de la comunidad.

Con la agudización de la crisis, por un lado, se reducen las posibilidades de los emigrantes de apoyar a su pueblo y, por otro, aumentan las demandas de apoyo; a falta de elementos para el "sistema de cargos" los pobladores han decidido incorporar a los emigrantes. Sin embargo, para que persista la unidad entre los pobladores y los migrantes, creemos que las alternativas deben decidirse entre ambas partes.

Por otra parte, en 1990 se detectan aproximadamente 20 inmigrantes mixes (principalmente de las comunidades de Tlahuitoltepec) que se contratan para trabajos agrícolas y de albañilería, y participan en el "tequio" y en los puestos menores dentro del "sistema de cargos", lo que implica una relación interétnica que introduce cambios socioculturales en la comunidad.

Por último, como síntesis de todo lo anterior se agrega que desde que el hombre era nómada lo que buscaba era la sobrevivencia y la convivencia, mismas que dependen de condiciones socioeconómicas y de la distribución o redistribución de los grupos sociales. De ahi que el presente trabajo hace explícito que la dinámica socioeconómica y la migración constituyen un solo proceso, en el que una condiciona a la otra y viceversa en determinados espacios geográficos y temporales. En el caso de Zoogocho, si partimos de que sus fundadores proceden de otro núcleo de población, encontramos desde ahí el desplazamiento poblacional, lógicamente que con otras características totalmente direrentes a las actuales.

Las correlaciones entre los elementos que intervienen tanto en la estructura socioeconómica como en la migración son las que determinan las diversas características que adopta el proceso en la historia. Actualmente la comunidad de Zoogocho está viviendo una serie de transformaciones socioeconómicas y culturales emanadas de un proceso que nadie puede detener, y que para poder sobrevivir y desenvolverse en él como zoogochense es fundamental mantener y fortalecer la unidad entre los emigrantes y los habitantes en su relación con el exterior, con la sociedad dominante que en última instancia responde a las necesidades e intereses del imperialismo norteamericano. 


\section{Bibliografía}

Alba, Francisco et al. (1979). Indocumentados: mitos y realidades, México, E] Colegio de México.

Arizpe, Lourdes (1978). Migración, etnicismo y cambio económico, México, El Colegio de México.

(1985). Campesinado y migración, México, SEP.

Berg Jr. y Richard Lewis (1974). El impacto de la economía moderna sobre la economía tradicional de Zoogocho, Oaxaca y su área circundante, trad. de Victoria Miret y Ana Zagury, México, INI.

Dehouve, Danièle (1980). El tequio de los santos y la competencia entre los mercaderes, trad. de Ellya Carola Cisneros de Ruzo, México, INı.

Díaz-Polanco, Héctor et al. (1980). Indigenismo, modernización y marginalidad. Una revisión crítica, México, cils y Juan Pablos Editor.

Meillassoux, Claude [1981). Mujeres, graneros y capitales, trad. de Óscar del Barco, México, Siglo XXI Editores.

Moguel, Reyna (1974). Regionalizaciones para el estado de Oaxaca. Análjsis comparativo, México, Centro de Sociologia, UABjo.

Morales, Patricia (1982). Indocumentados mexicanos, México, Editorial Grijalbo.

Muñoz, Humberto et al. (1977). Migración y desigualdad social en la ciudad de México, México, liunam y El Colegio de México.

Nader, Laura et al. (1985). Zapotecos, mixes y chinantecos, trad. de María José García Ripoll, México, Dirección General de Culturas Populares de la SEP, Unidad Regional Oaxaca-Instituto de Investigaciones Sociológicas de la UABJO, Oaxaca.

Ríos Hernández, Onésimo (1979). La sierra de Juárez, s.e., México.

Ríos Morales, Manuel (1985). Régimen capitalista e indígenas en la montaña de Guerrero, Historia de Guerrero I, México, UAG.

Romer Z., Martha [1982]. Comunidad, migración y desarrollo. El caso de los mixes de Totontepec, México, INI.

Stavenhagen, Rodolfo (1979). Problemas étnicos y campesinos, México, INI.

Revistas

Anales del Instituto Nacional de Antropología e Historia, t. III, México, INAH-SEP, 1949.

Estudios Sociológicos, vol. 1, núm. 3, México, El Colegio de México, septiembre-diciembre, 1983.

México Indígena, núm. 13, año 2, México, INI, noviembre-diciembre, 1986.

Cuadernos del CES, núm. 9, México, E] Colegio de México, 1976.

Fuentes documentales

Anuarios Estadísticos de Oaxaca, 1985 y 1987.

Censos Generales de Población y Vivienda, 1940, 1950, 1960, 1970, 1980 y 1990 (Resultados preliminares).

Censo Poblacional de Zoogocho, Oaxaca, 1987. 